Published in final edited form as:

Lancet. 2005 December 3; 366(9501): 1965-1976.

\title{
Marfan's syndrome
}

\author{
Daniel P Judge, MD \\ Division of Cardiology, Department of Medicine, Johns Hopkins University, Baltimore, MD 21205, \\ USA \\ Harry C Dietz, MD \\ McKusick-Nathans Institute of Genetic Medicine, Johns Hopkins University, Baltimore, MD 21205, \\ USA
}

\section{Abstract}

Marfan's syndrome is a systemic disorder of connective tissue caused by mutations in the extracellular matrix protein fibrillin 1. Cardinal manifestations include proximal aortic aneurysm, dislocation of the ocular lens, and long-bone overgrowth. Important advances have been made in the diagnosis and medical and surgical care of affected individuals, yet substantial morbidity and premature mortality remain associated with this disorder. Progress has been made with genetically defined mouse models to elucidate the pathogenetic sequence that is initiated by fibrillin-1 deficiency. The new understanding is that many aspects of the disease are caused by altered regulation of transforming growth factor $\beta$ (TGF $\beta$ ), a family of cytokines that affect cellular performance, highlighting the potential therapeutic application of TGF $\beta$ antagonists. Insights derived from studying this mendelian disorder are anticipated to have relevance for more common and nonsyndromic presentations of selected aspects of the Marfan phenotype.

Marfan's syndrome is a systemic disorder of connective tissue, first described more than 100 years ago by a Parisian professor of paediatrics, Antoine-Bernard Marfan, who reported the association of long slender digits and other skeletal abnormalities in a 5-year-old girl, Gabrielle. ${ }^{1}$ Today, the disorder that bears his name has benefited from decades of clinical and molecular investigation. This review will highlight the clinical manifestations, molecular pathogenesis, standard treatment, and emerging therapeutic options for this multisystem disorder.

\section{Epidemiology}

The incidence of classic Marfan's syndrome is about 2-3 per 10000 individuals, although this estimate depends on complete recognition of all affected and genetically predisposed individuals. Gray reported the incidence in Scotland as one in 9802 livebirths. ${ }^{2}$ Various factors could have contributed to an underestimate of disease prevalence. First, the phenotype becomes more apparent with increasing age in most families. Second, many of the outward manifestations are common in the general population and many physicians miss the diagnostic significance of these findings. Third, while the disorder segregates as a dominant trait in families, about $25 \%$ of cases are sporadic due to de-novo mutations; a family history of Marfan's syndrome is not always present as an obvious risk factor. Fourth, although it is known that mutations in the FBN1 gene, which encodes the matrix protein fibrillin 1, are the predominant (if not the sole) cause of classic Marfan's syndrome, there is no rapid and efficient molecular diagnostic test. ${ }^{3,4}$

Correspondence to: Harry C Dietz, hdietz@jhmi.edu.

Conflict of interest statement We declare that we have no conflict of interest. 
The disease occurs worldwide, with no predilection for either sex. Tall stature with dolichostenomelia (long-bone overgrowth) leads to increased incidence in certain athletes, including basketball and volleyball players, sometimes prompting a recommendation for screening by echocardiography. ${ }^{5}$ Kinoshita and co-workers ${ }^{5}$ screened 415 basketball and volleyball athletes in high school, college, or professional sports. Of these, four (1\%) had aortic enlargement, with a diameter greater than $4.6 \mathrm{~cm}$ at the aortic root, and two were diagnosed with Marfan's syndrome. Aortic enlargement was diagnosed independent of body surface area in this analysis. Although outdated criteria for the clinical diagnosis of the disorder were used, these data seem to indicate an increased incidence in this select population.

Because of the high incidence of aortic root aneurysm with associated risk of life-threatening aortic dissection, lifespan is often shortened. Before the successful use of surgical aortic root replacement, death from aortic dissection was far more common than it is today. A report in the early 1970s on life expectancy and cause of death in Marfan's syndrome describes that life expectancy for affected individuals was about two-thirds that of unaffected individuals, with life-table mortality curves deviating in infancy between controls and affected individuals. ${ }^{6}$ Cause of death was cardiovascular (aortic dissection, congestive heart failure, or cardiac valve disease) in over $90 \%$ of cases. However, a more recent assessment of outcome in Marfan's syndrome describes a nearly normal life expectancy, indicating improvement in the recognition and treatment of these conditions. 7

\section{Clinical manifestations}

Marfan's syndrome is a multisystem disorder with manifestations typically involving the cardiovascular, skeletal, and ocular systems. A consensus opinion regarding diagnostic criteria was outlined at the International Nosology of Heritable Disorders of Connective Tissue Meeting in Berlin in $1986 .{ }^{8}$ However, the recognition that many individuals diagnosed with the disorder do not carry the $F B N 1$ mutation identified in more severely affected family members led to revised criteria several years later that were more specific and stringent (panel). These criteria placed greater emphasis on the diagnostic use of skeletal findings and a requirement that a positive family history of the disorder could only be used as a major criterion for diagnosis of a proband if at least one family member independently satisfied diagnostic criteria on the basis of physical manifestations alone. ${ }^{9}$

\section{Search strategy and selection criteria}

The material covered in this review is based on extensive review of published works, including journals and textbook articles, as well as our ongoing investigation in this area. For PubMed searches we used the search term "Marfan". We did not restrict our search by language, and, when possible, references within the past 5 years were chosen.

\section{Panel: Diagnostic criteria for Marfan's syndrome}

\section{Index case}

- If the family/genetic history is not contributory, major criteria in two or more different organ systems and involvement of a third organ system.

- If a mutation known to cause Marfan's syndrome in others is identified, one major criterion in an organ system and involvement of a second organ system.

\section{Relative of an index case who independently meets these strict diagnostic criteria}

- Presence of a major criterion in the family history, one major criterion in an organ system, and involvement of a second organ system. 
Organ systems

At least four of the following constitutes a major criterion in the skeletal system

- Pectus carinatum

- Pectus excavatum, needing surgery

- Reduced upper-segment to lower-segment ratio or arm span to height ratio $>1.05$

- Wrist and thumb signs

- Scoliosis of $>20^{\circ}$ or spondylolisthesis

- Reduced extension at the elbows $\left(<170^{\circ}\right)$

- Medial displacement of the medial malleolus, causing pes planus

- Protrusio acetabulae of any degree (ascertained on radiographs)

Minor criteria

- Pectus excavatum of moderate severity

- Joint hypermobility

- Highly arched palate with crowding of teeth

- Facial appearance (dolichocephaly, malar hypoplasia, enophthalmos, retrognathia, down-slanting palpebral fissures)

For involvement of the skeletal system, at least two features contributing to major criteria, or one feature from the list contributing to the major criterion and two of the minor criteria must be present.

\section{Major criterion}

- Ectopia lentis

\section{Minor criteria}

- Abnormally flat cornea

- Increased axial length of globe

- Hypoplastic iris or hypoplastic ciliary muscle, causing decreased miosis

For involvement of the ocular system, at least two of the minor criteria must be present.

\section{Major criteria (either of the following)}

- Dilatation of the ascending aorta, with or without aortic regurgitation, and involving at least the sinuses of Valsalva

- Dissection of the ascending aorta

\section{Minor criteria}

- Mitral valve prolapse with or without mitral valve regurgitation

- Dilatation of the main pulmonary artery, in the absence of valvular or peripheral pulmoni stenosis or any other obvious cause, younger than age 40 years

- Calcification of the mitral annulus younger than age 40 years 


Dilatation or dissection of the descending thoracic or abdominal aorta younger
than age 50 years
For involvement of the cardiovascular system, only one of the minor criteria must be present.
Major criteria
- None
Minor criteria
- Spontaneous pneumothorax
- Apical blebs
For involvement of the Pulmonary system, only one of the minor criteria must be present
Major criteria
- None
Minor criteria
- Striae atrophicae (stretch marks) without marked weight gain, pregnancy, or
- repetitive stress
Recurrent or incisional herniae
For involvement of the skin and integument, only one of the minor criteria must be present
Major criterion
- $\quad$ Lumbosacral dural ectasia
Minor criteria
Minor criteria
Major criteria (any one of the following)
- None

\section{Skeletal system}

Disproportionate overgrowth of the long bones is often the most striking and immediately evident manifestation. Anterior chest deformity is caused by overgrowth of the ribs, pushing the sternum anteriorly (pectus carinatum) or posteriorly (pectus excavatum). Overgrowth of arms and legs can lead to an arm span greater than 1.05 times the height or a reduced upper to lower segment ratio (in the absence of severe scoliosis). Arachnodactyly (overgrowth of the fingers) is generally a subjective finding. The combination of long fingers and loose joints leads to the characteristic Walker-Murdoch or wrist sign: full overlap of the distal phalanges of the thumb and fifth finger when wrapped around the contralateral wrist. The Steinberg or thumb sign is present when the distal phalanx of the thumb fully extends beyond the ulnar border of the hand when folded across the palm. Although commonly present, thoracolumbar 
scoliosis must be sufficiently severe $\left(>20^{\circ}\right)$ to contribute to the skeletal criteria for the syndrome. Protrusio acetabuli, which is generally asymptomatic in young adults, is best identified with radiographic imaging. ${ }^{10}$ Pes planus (flat feet) are frequently present, and vary from mild and asymptomatic to severe deformity wherein medial displacement of the medial malleolus results in collapse of the arch and often reactive hip and knee disturbances. Curiously, a subset of individuals with the disorder present with an exaggerated arch, pes cavus. Although joint laxity or hypermobility is frequently identified, joints can be normal or even develop contractures. Reduced extension of the elbows is common and can contribute to the designation of major involvement of the skeleton. Contracture of the fingers (camptodactyly) is also commonly observed, especially in children with severe and rapidly progressive Marfan's syndrome. Several craniofacial manifestations are frequently present, but are not specific enough to the disorder for inclusion in the major criteria. These include a long narrow skull (dolicocephaly), a high-arched palate, tooth crowding, retrognathia (recessed lower mandible) or micrognathia (small chin), malar flattening, and downward-slanting palpebral fissures.

\section{Ocular system}

A major criterion is present with ectopia lentis (dislocation of the ocular lens) of any degree, although, once again, this condition is not unique to Marfan's syndrome. Ectopia lentis has been shown to occur in around $60 \%$ of patients with the disorder. ${ }^{11}$ When identified, it should prompt further assessment for Marfan's syndrome, although homocystinuria, WeillMarchesani, and familial ectopia lentis are also associated with this condition. Other manifestations of the ocular system include early and severe myopia, flat cornea, increased axial length of the globe, hypoplastic iris, and ciliary muscle hypoplasia, causing decreased miosis. Individuals with Marfan's syndrome can also have retinal detachment and a predisposition for early cataracts or glaucoma.

\section{Cardiovascular system}

Manifestations of Marfan's syndrome in the cardiovascular system are conveniently divided into those affecting the heart and those affecting the vasculature. ${ }^{12}$ Within the heart, the atrioventricular valves are most often affected. Thickening of the atrioventricular valves is common and often associated with prolapse of either the mitral or tricuspid valves or both atrioventricular valves. Variable degrees of regurgitation may be present. In children with early onset and severe Marfan's syndrome, insufficiency of the mitral valve can lead to congestive heart failure, pulmonary hypertension, and death in infancy; this insufficiency represents the leading cause of morbidity and mortality in young children with the disorder. ${ }^{13}$ A survey of 166 patients with apparent Marfan's syndrome (mean age 11.9 years), identified more than half of them to have auscultatory or echocardiographic evidence of mitral valve dysfunction, most commonly prolapse. ${ }^{14}$ In this same analysis, more than $25 \%$ of these individuals had progression of mitral valve prolapse to mitral regurgitation by adulthood, with twice as many women as men progressing in their mitral valve dysfunction. ${ }^{14}$ Calcification of the mitral annulus in individuals younger than age 40 years constitutes a minor criterion in the cardiovascular system.

Aortic valve dysfunction is generally a late occurrence, attributed to stretching of the aortic annulus by an expanding root aneurysm. Both the aortic and atrioventricular valves seem to be more prone to calcification in individuals with Marfan's syndrome. ${ }^{14,15}$ Ventricular dysrhythmia has been described among a small cohort of children with the disorder. ${ }^{16}$ In association with mitral valve dysfunction, supraventricular arrhythmia, such as atrial fibrillation, may be seen. Several groups have described increased prevalence of prolonged QT interval on electrocardiographic surveys of patients with Marfan's syndrome. 16,17 
Dilated cardiomyopathy, beyond that explained by aortic or mitral valve regurgitation, seems to occur with increased prevalence in patients with Marfan's syndrome, perhaps implicating a role of the extracellular matrix protein fibrillin 1 in the cardiac ventricles. However, the occurrence rate seems to be low, and the occurrence of mild to moderate ventricular systolic dysfunction is often attributed to mitral or aortic insufficiency, or to the use of $\beta$ adrenergic receptor blockade. Meijboom and colleagues ${ }^{18}$ reported their findings in 234 patients with the disorder, without significant valve disease or aortic root surgery. They identified 17 of these people with left ventricular enlargement, but none had fractional shortening less than $25 \%$, with an average age among the cohort of 29 years (SD 11).

Aortic aneurysm and dissection remain the most life-threatening manifestations of Marfan's syndrome. This finding is age dependent, prompting life-long monitoring by echocardiography or other imaging modalities. Dilatation at the sinuses of Valsalva can begin in utero in severe cases, although some unequivocally affected individuals never reach an aortic size that needs surgical intervention. By contrast with atherosclerotic aneurysms and some other forms of ascending aortic aneurysms, dilatation is generally greatest at (and often restricted to) the aortic root. Normal aortic dimensions vary with both age and body size; proper interpretation of aortic dimensions needs comparison to age-dependent nomograms (figure). ${ }^{19}$ The two most important determinants of risk of dissection of the aorta are the maximal dimension and family history of dissection. Surgical repair of the aorta is recommended when its greatest diameter reaches about $50 \mathrm{~mm}$ in adults. ${ }^{20,21}$ Early intervention is considered in the presence of a family history of early dissection. There are no definitive methods to guide the timing of surgery in childhood. The observation that dissection is extremely rare in this age-group irrespective of aortic size has prompted many centres to adopt the adult criterion of $50 \mathrm{~mm}$. Early surgery is often undertaken given a rapid rate of growth ( $>1 \mathrm{~cm}$ in a year) or the emergence of significant aortic regurgitation. Most patients with acute aortic dissection have classic symptoms, including severe chest pain, often radiating along the path of dissection. ${ }^{22}$ This path almost invariably begins at the aortic root (type A) and dissection can remain isolated (type II) or propagate along the length of the descending aorta (type I). ${ }^{23}$ Acute onset congestive heart failure typically indicates severe aortic valve insufficiency, complicating the aortic dissection. Depending on the involvement of the carotid arteries, some patients can have neurological sequelae due to cerebrovascular injury. Involvement of the coronary arteries can lead to myocardial infarction or sudden cardiac death. The mechanism of death usually includes rupture into the pericardial sac with subsequent pericardial tamponade. Chronic aortic dissection and intimal tears usually present more insidiously, often without chest pain.

Dilatation of the main pulmonary artery, in the absence of valvular or peripheral pulmonic stenosis, or any other obvious cause, at age younger than 40 years, constitutes a minor criterion in the cardiovascular system. Dilatation or dissection of the descending thoracic or abdominal aorta at age younger than 50 years is also regarded as a minor criterion in the cardiovascular system.

\section{Pulmonary system}

Several factors can result in pulmonary disease in patients with Marfan's syndrome. Pectus excavatum or progressive scoliosis can contribute to a restrictive pattern of lung disease. 24 Widening of the distal airspaces with or without discrete bullae or (often apical) blebs can predispose to spontaneous pneumothorax, which is found in 4-15\% of patients with the disorder. ${ }^{25}$ During assessment of pulmonary volumes and function, one must recognise that long-bone overgrowth affecting the lower extremities can lead to reduction in the normalised forced vital capacity and total lung capacity. However, if normalised to thoracic size or sitting height, pulmonary function testing is often normal in patients with the disorder. ${ }^{24}$ 


\section{Skin and integument}

By contrast with several other connective tissue disorders, such as the Ehlers-Danlos syndromes, patients with Marfan's syndrome typically have normal skin texture and elasticity. The most common manifestation in the skin is striae atrophicae, which occurs in about twothirds of patients. ${ }^{26}$ By contrast with striae in those without a connective tissue disorder, stretch marks tend to occur in the absence of obesity, rapid gain in muscle mass, or pregnancy, and at sites not associated with increased skin distension (eg, the anterior shoulder area and the lower back). Another common manifestation is inguinal hernia, either occurring at birth or acquired in adolescence. There is an increased risk of surgical and recurrent hernias in the Marfan population.

\section{Dural ectasia}

Widening of the dural sac or root sleeves constitutes ectasia of the dura, which is present in 63-92\% of people with the disorder. ${ }^{27-29}$ Although dural ectasia can result in lumbar back pain, it is often asymptomatic and should be assessed by lumbosacral imaging with CT or MRI. When present, it constitutes a major criterion for the clinical diagnosis of Marfan's syndrome, although the specificity and predictive value of this finding are not known. Incidence of dural ectasia in other heritable disorders of connective tissue has not been rigorously assessed, although the results of one trial indicate that $24 \%$ of patients with Ehlers-Danlos syndrome had dural ectasia. 28

\section{Family/genetic history}

By contrast with the consensus criteria for Marfan's syndrome established in 1986, the revised criteria emphasise the need for a first-degree relative to independently meet criteria before including family history as a major criterion for the diagnosis of the disorder. The presence of an FBN1 mutation or the segregation of a haplotype around the FBNI locus, inherited by descent and unequivocally associated with a relative diagnosed with Marfan's syndrome in the family, constitutes a major criterion in the diagnosis of the disorder.

\section{Differential diagnosis}

Several disorders are included in the differential diagnosis of Marfan's syndrome on the basis of similar skeletal, cardiac, or ophthalmological manifestations (table). Many individuals referred for possible Marfan's syndrome are shown to have evidence of a systemic disorder of the connective tissue, including long limbs, deformity of the thoracic cage, striae atrophicae, mitral valve prolapse, and mild and non-progressive dilatation of the aortic root, but do not meet diagnostic criteria for the disorder. This constellation of features, not fulfilling the diagnostic requirements of the disorder, is referred to by the acronym MASS phenotype, emphasising the mitral, aortic, skin, and skeletal manifestations. ${ }^{30}$ MASS phenotype can segregate in large pedigrees and remain stable over time. This diagnosis is most challenging in the context of an isolated and young individual. In this setting, careful follow-up is needed to distinguish MASS phenotype from emerging Marfan's syndrome, especially in children. Other fibrillinopathies, such as familial mitral valve prolapse syndrome and familial ectopia lentis, also include subclinical manifestations and can be due to mutations in the gene encoding fibrillin $1.31,32$

Also included in the differential diagnosis of the disorder is homocystinuria caused by a deficiency of cystathionine $\beta$ synthase. Patients with homocystinuria often have tall stature, long-bone overgrowth, and ectopia lentis, but do not typically have aortic enlargement or dissection. By contrast with Marfan's syndrome, the inheritance of homocystinuria is autosomal recessive, and affected individuals often have mental retardation, a predisposition 
to thromboembolism, and a high incidence of coronary artery atherosclerosis. Observation of severely raised concentrations of plasma homocystine is an efficient mechanism to distinguish homocystinuria from Marfan's syndrome.

Familial thoracic aortic aneurysm syndrome segregates as a dominant trait and can show vascular disease identical to that seen in Marfan's syndrome, including aortic root aneurysm and dissection. These individuals generally do not show any of the systemic manifestations of Marfan's syndrome. 33,34 Other families show the association between bicommissural aortic valve and ascending aortic aneurysm, which can also segregate as a dominant trait. ${ }^{35}$ Here, maximum dilatation often occurs further up in the ascending aorta, beyond the sinotubular junction. There is emerging evidence that the bicommissural aortic valve and aneurysm both represent primary manifestations of a single gene defect, and that family members of a proband can show aneurysm without the accompanying valve abnormality. Once again, affected individuals do not show systemic features of a connective tissue disorder. Unlike Marfan's syndrome, families with both thoracic aortic aneurysm syndrome and with bicommissural aortic valve and ascending aortic aneurysm show reduced penetrance and variable onset of aortic dilatation. Although genetic loci have been described for thoracic aortic aneurysm syndrome, no specific genes (or molecular tests) have been described for these disorders, mandating ongoing follow-up of all at-risk family members. 33,34 The management principles that have been generated for Marfan's syndrome have proven effective for these other forms of familial aortic aneurysm.

A clear exception to this rule applies to an aortic aneurysm syndrome that associates some systemic features of Marfan's syndrome with other features that are quite unique. ${ }^{36}$ As in Marfan's syndrome, patients with Loeys-Dietz aortic aneurysm syndrome show malar hypoplasia, arched palate, retrognathia, pectus deformity, scoliosis, joint laxity, dural ectasia, and aortic root aneurysms and dissection. Although their fingers tend to be long, overgrowth of the long bones can be subtle and is often absent. These patients do not show ectopia lentis. Unique features include a high frequency of hypertelorism, broad or bifid uvula, arterial tortuosity, and aneurysms with dissection throughout the arterial tree. The aneurysms often dissect at sizes not associated with risk in Marfan's syndrome, and frequently lead to death in young childhood. Other less consistent features include blue sclerae, translucent skin, easy bruising, craniosynostosis, cleft palate, Chiari type I malformation of the brain, learning disability, congenital heart disease (patent ductus arteriosus, atrial septal defect, bicommissural aortic valve), and clubfoot deformity.

There is significant overlap between Loeys-Dietz aortic aneurysm syndrome and the Shprintzen-Goldberg syndrome that includes craniosynostosis, hypertelorism, arched palate, learning disability, bone overgrowth, pectus deformity, and scoliosis. 36,37 Vascular disease is described as a rare manifestation of Shprintzen-Goldberg syndrome. ${ }^{38}$ Furlong and colleagues ${ }^{39}$ described one patient with Marfanoid habitus, craniosynostosis, hypertelorism, normal intelligence, and aortic root aneurysm with dissection. ${ }^{39}$ Relative to other aortic diseases, features unique to Loeys-Dietz aortic aneurysm syndrome include cleft palate, bifid uvula, arterial tortuosity, and diffuse aneurysms and dissections. ${ }^{36}$ In view of the aggressive behaviour of vascular disease, the distinction of Loeys-Dietz aortic aneurysm syndrome is essential to individualise management.

\section{Molecular genetics and pathophysiology}

Both skin and aorta from patients with Marfan's syndrome show decreased elastin content and fragmentation of elastic fibres. ${ }^{40-42}$ However, phenotypic manifestations in tissues without elastin, such as ciliary zonules and bone, helped to exclude the elastin gene as the primary site 
of mutations causing the disorder. Additionally, linkage analysis mapped the Marfan's syndrome locus to $15 \mathrm{q} 21.1$, distant from the chromosomal locus of elastin at $7 q 11.2 .43,44$

Sakai and colleagues 45 first identified fibrillin 1 as the principal component of the extracellular matrix microfibril, present in all tissues with phenotypic manifestations of the disorder. In 1991 , mutational analysis of FBNI in patients with Marfan's syndrome resulted in the identification of two unrelated patients with identical, de novo, missense mutations. ${ }^{3}$ To date, both extensive linkage and comprehensive mutation analyses indicate the absence of locus heterogeneity for the classic Marfan phenotype. ${ }^{4,32,46}$ Most families have unique or private mutations.

The fibrillin 1 gene contains 65 exons spanning $235 \mathrm{~kb}$ of genomic DNA. ${ }^{47,48}$ It encodes a $350 \mathrm{kDa}$ glycoprotein, which is highly conserved among different species. Most mutations occur within the 47 tandemly repeated epidermal growth factor-like domains, many disrupting one of the six predictably spaced cysteine residues that interact via disulfide linkage to determine domain folding or residues that affect calcium binding to fibrillin 1 . Such perturbations lead to enhanced cleavage and proteolytic degradation. 49,50

Several findings suggested that dominance in Marfan's syndrome is caused by adverse activity of the mutant protein on the deposition, stability, or function of the normal protein encoded by the normal copy of the FBN1 gene-a so-called dominant-negative effect. First, this was a well-established framework for other connective tissue disorders, such as type I collagen defects, causing osteogenesis imperfecta. Second, fibrillin-1 monomers aggregate to form complex structures called microfibrils, providing an opportunity for interference. Third, tissues from affected patients often have a dramatic paucity of fibrillin-1, far less than $50 \%$ that would be predicted from simple loss of contribution of one allele. ${ }^{51}$ Fourth, some patients with mutations associated with low production of mutant protein have a mild, subdiagnostic variant of the disorder. 52,53 However, this association between abundance of mutant transcript and severity of disease was refuted by the report of patients with classic severe disease and very low levels of mutant transcripts containing a premature termination codon. 54

Evidence suggests that half-normal production of normal protein (haploinsufficiency), rather than the production of mutant protein, could be critical to reach the threshold loss of fibrillin-1 function needed for clinical expression of the disorder. First, transgenic overexpression of mutant fibrillin 1, in the context of two normal Fbnl alleles, was shown to be insufficient to cause the vascular changes of Marfan's syndrome seen in mice heterozygous for a comparable missense mutation (C1039G) ${ }^{55}$ Second, mice heterozygous for a null Fbnl allele showed similar alterations in aortic wall architecture as C1039G/+ mice (Ramirez F, Hospital for Special Surgery, New York, USA, personal communication). Finally, the transgenic addition of a wild-type allele to $\mathrm{C} 1039 \mathrm{G}$ heterozygous mice rescued the aortic phenotype. ${ }^{55}$ Thus, a normal complement of fibrillin 1 might be needed to initiate productive microfibrillar assembly. Although the haploinsufficiency-imposed reduction in microfibrillar abundance may or may not be sufficient in isolation to lead to classic Marfan's syndrome, it seems critical to the context within which a dominant negative effect can achieve clinical significance. These data suggest that boosting fibrillin-1 expression could be a productive therapeutic strategy and implicate genetic modifiers in the modulation of disease severity. For example, Hutchinson and colleagues 56 have described a family with Marfan's syndrome in whom phenotypic severity correlated inversely with the expression level of fibrillin 1 by the allele without a mutation.

Murine models of Marfan's syndrome have provided the opportunity to assess some of the earliest pathogenetic abnormalities resulting in aneurysm and dissection. 57,58 They have shown that fibrillin-1 microfibrils are not needed to assemble an elastic fibre, as previously 
inferred. This model had suggested that infants with the disorder are born without assembled elastic fibres-in essence an obligate structural predisposition for tissue failure later in life. This notion boded poorly for the development of productive treatment strategies. Rather, microfibrils are needed to maintain elastic fibres during postnatal life. In the absence of proper connections between elastic fibres and vascular smooth-muscle cells mediated by fibrillin 1 , the cells adopt an abnormal synthetic repertoire that includes matrix-degrading enzymes, such as matrix metalloproteinases 2 and 9. Subsequent events include elastic fibre calcification, vascular wall inflammation, intimal hyperplasia due to migration and proliferation of vascular smooth-muscle cells, and structural collapse of the vessel wall. Similar vascular pathology has been identified in large muscular arteries from seven patients diagnosed with the disorder. 59

In addition to the obvious structural role of fibrillin-1-rich microfibrils, it is becoming increasingly clear that these microfibrils also have a critical role in regulation of cytokines, molecules that affect tissue development and homoeostasis via regulation of cellular performance - proliferation, migration, synthetic repertoire, and death. ${ }^{60}$ Fibrillin 1 shares a high degree of homology with the latent transforming growth factor $\beta$ (TGF $\beta$ ) binding proteins. 61 The TGF $\beta$ cytokines are secreted as large latent complexes, consisting of TGF $\beta$, latencyassociated peptide, and one of three latent TGF $\beta$-binding proteins. ${ }^{62}$ On secretion, the large latent complex is sequestered by the extracellular matrix. TGF $\beta$ signalling requires release of the mature cytokine, interaction with cell-surface receptors, and initiation of a downstream signalling cascade. ${ }^{63}$ The homology between the fibrillins and latent TGF $\beta$-binding proteins prompted the hypothesis that extracellular microfibrils might participate in the regulation of TGF $\beta$ activation. This proposal was advanced through study of distal airspace enlargement in fibrillin-1-deficient mice. Similar pulmonary changes occur in Marfan's syndrome and have been attributed to the effects of physiological stress acting on a structurally predisposed tissue -ie, classic destructive emphysema. Subsequent analyses in fibrillin-1-deficient mice showed that airspace enlargement manifested a primary failure of distal alveolar septation during lung morphogenesis in the absence of lung inflammation or destruction. ${ }^{64}$ These animals showed a substantial increase in both free TGF $\beta$ and TGF $\beta$-signalling at a developmental stage relevant to alveolar septation. Furthermore, administration of TGF $\beta$-neutralising antibody was sufficient to rescue septation in fibrillin 1-deficient mice. ${ }^{64}$

It seemed plausible that this pathogenetic mechanism was relevant to other manifestations of Marfan's syndrome- especially those that were difficult to reconcile on the basis of pathogenetic models that singularly invoke structural failure of the tissues. Likely candidates included bone overgrowth, myxomatous changes of the mitral valve, craniofacial abnormalities, and muscle or fat hypoplasia. Increased local activity of TGF $\beta$ has recently been shown to be responsible for the myxomatous cardiac valve disease in fibrillin-1-deficient mice. ${ }^{65}$ As demonstrated in the lungs, atrioventricular valve lengthening, thickening, and dysfunction is prevented when TGF $\beta$-neutralising antibody is given to mouse models of Marfan's syndrome. Increased TGF $\beta$ activity has also been recorded in other tissues, including the vasculature and the dura. 66

Further evidence for the broad relevance of dysregulated TGF $\beta$ signalling came with the identification of the genetic defect in a subset of patients previously characterised as having classic Marfan's syndrome and all individuals with Loeys-Dietz aortic aneurysm syndrome. 36,67 First, Mizuguchi and colleagues ${ }^{67}$ described that mutations in the gene encoding the type II TGF $\beta$ receptor (TGFBR2) exactly recapitulate the classic Marfan phenotype. While the presentation of these individuals is atypical for Marfan's syndrome (eg, absence of lens dislocation, normal height, lack of dolichostenomelia, high rate of non-penetrance), the researchers reported heterozygous loss-of-function mutations in patients with many features of the disorder. It was difficult, however, to reconcile the inferred mechanism of decreased TGF $\beta$ signalling with the increase seen in mouse models of Marfan's syndrome. ${ }^{64-66}$ Loeys 
and colleagues ${ }^{36}$ went on to show that all patients with Loeys-Dietz aortic aneurysm syndrome were heterozygous for loss-of-function mutations in either of the genes encoding the type I or type II TGF $\beta$ receptor (TGFBRI or TGFBR2). Furthermore, heterozygosity for these mutations did not impair responsiveness to TGF $\beta$ in cultured cells from patients and led paradoxically to enhanced signalling in the aortic wall, as seen in both mice and people deficient for fibrillin 1 .

\section{Clinical genetic testing}

The role of genetic testing in establishing a diagnosis remains limited. To date, over 500 mutations resulting in the disorder have been catalogued in an international database. ${ }^{68}$ Over $90 \%$ are private mutations unique to an individual or family. Even within families where all affected individuals share the same mutation, phenotypic variation is prominent. Thus, it is difficult to derive significant genotype-phenotype correlations. ${ }^{69}$ Due to the large size of FBNI (65 exons), the cost of routine sequence analysis of all exons could be prohibitive. By contrast, haplotype segregation analysis may be done more easily, and could provide the desired information regarding who in the family has inherited the predisposing copy of the FBN1 gene. ${ }^{70,71}$ However, around $25 \%$ of patients with the disorder have a de-novo mutation, limiting the feasibility of haplotype segregation analysis.

As previously mentioned, many other conditions can be caused by mutations in FBNI, including MASS phenotype, Shprintzen-Goldberg syndrome, mitral valve prolapse syndrome, familial ectopia lentis, isolated Marfanoid habitus, and Weill Marchesani syndrome. 30,31, 72,73 However, mutations in ADAMTS10 have also been described as causing Weill Marchesani syndrome, and many patients with Shprintzen-Goldberg syndrome have not been shown to have a mutation in $F B N 1$, thus exhibiting locus heterogeneity for these disorders.

74 Phenotype or severity are often difficult or impossible to predict simply on the basis of the nature or location of a mutation in FBN1. Furthermore, best estimates suggest that about $10 \%$ of mutations that cause classic Marfan's syndrome are missed by conventional screening methods. ${ }^{4}$ In essence, gene testing lacks both sensitivity and specificity. Under these circumstances, mutational or linkage analysis seems to be best used to identify who in a family has inherited the predisposition for the phenotype seen in that family. This notion extends to the use of molecular methods for prenatal diagnosis. ${ }^{75}$ At the present time, diagnosis is largely based on clinical assessment.

\section{Management}

The diagnosis of Marfan's syndrome requires a multidisciplinary assessment that generally includes a geneticist for general assessment and anthropomorphic measurements, an ophthalmologist for a slit-lamp examination, and a cardiologist for cardiovascular imaging. After establishing a clinical diagnosis of Marfan's syndrome, routine monitoring of aortic growth is essential to decrease the risk of aortic dissection. Yearly assessment by transthoracic echocardiography allows serial measurements of the proximal aorta, including the size of the aortic root at greatest dimension, the sinotubular junction, and the ascending aorta. Both the absolute size of the aorta in greatest diameter and the rate of growth of the aorta are monitored to establish the appropriate time to intervene surgically. At times, technical difficulties limit views of the proximal aorta, especially in patients with significant pectus deformity of the sternum. In such cases, CT angiography or MRI can provide accurate images of the proximal aorta, and should be used on at least a yearly basis. More frequent imaging is indicated if the aortic size is approaching a threshold that would initiate surgery or if rapid growth is observed.

While ectopia lentis is a major criterion in establishing a clinical diagnosis of Marfan's syndrome, these patients are also at increased risk of retinal detachment, glaucoma, and cataracts. Myopia is reported in most patients, and may predispose to amblyopia in early 
childhood. ${ }^{76}$ Thus, patients with the disorder should undergo comprehensive yearly assessments by an ophthalmologist, ideally with training or expertise in this disorder. Lens dislocation can generally be managed with eyeglasses or contact lenses; occasionally, surgical aphakia is needed to achieve adequate vision. ${ }^{77}$ This can be followed by artificial lens implantation once growth is complete.

Severe orthopaedic issues will need involvement of a skilled orthopaedist. Bracing is generally inadequate to manage severe and progressive scoliosis, which often requires surgical stabilisation. ${ }^{78}$ This situation must be monitored closely during growth. Pectus deformity is largely a cosmetic issue, although often significant enough to warrant surgery. ${ }^{79}$ Although many patients with pectus deformity have restrictive lung disease, some studies have shown little or no effect on lung capacity after repair. ${ }^{80,81}$ Others have suggested that improvement in symptoms could be due to increased cardiac function. ${ }^{82} \mathrm{~A}$ recent report of 45 patients who underwent minimally invasive surgical intervention (Nuss procedure) and bar removal for pectus excavatum described a significant increase in forced vital capacity after surgery, with improvement most prominent in patients aged older than 11 years. ${ }^{83}$ We have never observed a case where pectus excavatum was proven to critically impair cardiovascular function. Good cosmetic results for pectus excavatum can generally be achieved with the minimally invasive Nuss procedure. ${ }^{84}$ If done too early, however, continued rib growth will lead to recurrent deformity. 85

\section{Medical treatment to prevent or delay aortic aneurysm}

$\beta$-adrenergic receptor blockade to delay or prevent aortic aneurysm and dissection is currently regarded as the standard of care for patients with the disorder. This strategy was first proposed in 1971 by Halpern and colleagues. ${ }^{86}$ The rationale for this treatment strategy is primarily to decrease proximal aortic shear stress, or change in pressure over time $(\mathrm{dP} / \mathrm{dT}) . \beta$ blockers are probably beneficial both through negative inotropic and negative chronotropic effects. Although small, most published studies have shown benefit of treatment with $\beta$ blockers in Marfan's syndrome, including in children. ${ }^{87,88}$ The only randomised trial assessing the effect of $\beta$ blockade in patients with the disorder was published in $1994 .{ }^{89}$ Herein they describe 70 patients with the syndrome, and treated 32 with propranolol. Using an open-label protocol, treated patients received a dose of propranolol targeted for a heart rate below 100 beats per minute during exercise or resulting in a 30\% rise in the systolic time interval (corrected for the heart rate). Patients were analysed for aortic growth, with change in body size accounted for in an aortic ratio by dividing the measured aortic diameter by the diameter predicted from the patient's height, weight, and age. ${ }^{19,90}$ Fewer patients treated with propranolol reached a primary clinical endpoint of aortic regurgitation, aortic dissection, cardiovascular surgery, congestive heart failure, and death (five in treatment group, nine in control group).

Furthermore, the normalised rate of aortic dilatation was lower in the propranolol group than in the control group (0.023 vs 0.084 peryear, $\mathrm{p} \beta 0 \cdot 001)$.

A recent trial compared 58 patients treated with $\beta$ blocker (propranolol or atenolol) with those treated with an ACE-inhibitor, enalapril. Patients were not randomised and the dose of $\beta$ blocker was not titrated to physiological response. Aortic change was not reported with normalisation to body size. Although benefit was shown to be greater in those patients treated with enalapril rather than in those treated with $\beta$ blocker, most enalapril-treated patients were either newly enrolled or had discontinued $\beta$ blockers owing to intolerance. ${ }^{91}$ Whether this situation presented a bias, either due to low motivation to continue a $\beta$ blocker owing to smaller aortic sizes or slower growth rates or the inclusion of individuals who were not destined to develop aortic enlargement, is not known. In our practice, the dose of $\beta$ blocker needed to achieve a therapeutic response is highly variable and is not predicted by bodyweight or age. Failure to titrate the dose of medication represents a major limitation of this study. 
Around $10-20 \%$ of patients with Marfan's syndrome are intolerant to $\beta$ blockers. Reasons include asthma, depression, and fatigue. Among such individuals, a trial of verapamil may be justified on the basis of a report showing that such treatment can slow the rate of aortic growth, although this trial was non-randomised and uncontrolled. ${ }^{88}$ Among the trials that have assessed use of pharmacological therapy for aortic aneurysm in Marfan's syndrome, it is important to point out that aortic growth is not stopped or reversed, but typically is slowed in response to treatment. Thus, in the setting of aortic enlargement, despite treatment with pharmacological agents to slow the rate of aortic growth, one should remain vigilant for further aortic enlargement with at least yearly measures of aortic dimensions.

\section{Surgery for aortic aneurysm}

The rate of acute aortic dissection is directly proportional to the maximum diameter of the aorta. Elective surgery to repair the aortic root is recommended when the maximum aortic diameter reaches $5 \mathrm{~cm} .{ }^{21,92}$ Additional considerations include the rate of aortic growth and family history of aortic dissection at a size less than $5 \mathrm{~cm}$. Earlier surgical intervention is recommended for individuals with an increase in aortic diameter exceeding $1 \mathrm{~cm}$ per year.

Composite surgical replacement of the aortic root and valve was pioneered by Bentall and De Bono in 1968. ${ }^{93}$ Modifications of this technique have evolved with various methods of coronary reimplantation. ${ }^{94}$ Gott and colleagues ${ }^{21}$ reported outcomes for 675 patients with the disorder who underwent aortic root replacement surgery at ten experienced surgical centres (seven in North America and three in Europe). Mortality for elective surgery was 1.5\% compared with $2.6 \%$ for urgent surgery (taking place within 7 days after surgical consultation). Mortality was $11.7 \%$ among patients who underwent emergency surgery within $24 \mathrm{~h}$ after surgical consultation.

Due to risks of thromboembolism and the lifetime requirement of warfarin anticoagulation in the setting of a mechanical prosthetic aortic valve, recent surgical efforts, pioneered by David and colleagues, ${ }^{95}$ have attempted to maintain the native aortic valve among eligible patients with the disorder. ${ }^{95,96}$ To date, no randomised clinical trials of valve replacement versus valve-sparing aortic root surgery have been undertaken, and long-term data on the outcomes with valve-sparing surgery are not yet available. Nevertheless, the short-term data are encouraging, with an extremely low rate of operative mortality (equivalent to that seen with composite graft repair). ${ }^{97-99}$ The valve-sparing procedure has seen a tremendous evolution, largely focused on preserving function of the native aortic valve. Initial attempts to resuspend the valve into the Dacron graft were complicated by damage to the leaflets on maximum excursion. A remodelling procedure that involved sewing the graft to the top of the aortic annulus showed an unacceptable rate of valve splaying with subsequent dysfunction and reoperation. Most recently, a modified resuspension procedure is being employed with crafting of artificial sinuses above the valve. ${ }^{97,99,100}$ This procedure has shown excellent short-term results and is now the preferred treatment in all eligible patients who present for surgical intervention. The valve-sparing approach is especially attractive for young women who anticipate pregnancy.

\section{Lifestyle modifications}

Due primarily to the risk of acute aortic dissection, patients should be counselled not to engage in contact sports, competitive athletics, or isometric exercise. Sudden death in the setting of unrecognised Marfan's syndrome among several high profile athletes has helped to emphasise the importance of early recognition and activity limitations for this disorder. Most patients, however, should be encouraged to remain active with aerobic activities performed in moderation. This will promote skeletal, cardiovascular, and psychosocial health in the long 
term. More detailed descriptions of specific activities appropriate for patients with the disorder are reviewed elsewhere. 101,102

The issue of pregnancy in Marfan's syndrome draws attention to concerns about the risk of transmission of this disease. Genetic counselling should be undertaken and one should inform prospective parents of the 50\% risk of offspring of an affected individual inheriting a genetic predisposition to the disorder. Before current standards for surgical repair of the aortic root, early experience indicated a high risk of aortic dissection during pregnancy. ${ }^{103}$ More recent analyses have indicated that the risk of aortic enlargement is related to the size of the aortic root before pregnancy, and in the setting of an aortic root size less than $4 \mathrm{~cm}$, the risk of pregnancy is low. ${ }^{104,105}$ Finally, one should discuss the issue of anticoagulation and pregnancy with women who have Marfan's syndrome. Systemic anticoagulation with warfarin during pregnancy in the setting of a mechanical prosthetic aortic valve is associated with increased risk of fetal demise and warfarin embryopathy. ${ }^{106}$ Low molecular weight heparin, given subcutaneously during pregnancy, seems safer than warfarin as it does not cross the placenta, although it is expensive, can result in heparin-induced thrombocytopenia, and might not prevent prosthetic valve thrombosis. ${ }^{107-109}$ Pregnancy in patients with the disorder should precede significant aortic enlargement or follow a valve-sparing procedure. Close monitoring by an obstetrician and a cardiologist remains mandatory.

\section{New developments}

The prevailing view had been that people with Marfan's syndrome are born with a structural weakness of the tissues that imposes an obligate risk of tissue failure later in life. Strategies to strengthen the connective tissue throughout the body were difficult to conceive much less implement. The new realisation that Marfan's syndrome manifests postnatally acquired tissue pathology, and that this may largely indicate a failed regulatory (as opposed to structural) role of the extracellular matrix, presents a far more optimistic outlook. With the possible exception of ectopia lentis, most manifestations of Marfan's syndrome seem to implicate dysregulation of TGF $\beta$ activity and signalling. Furthermore, emerging data from mouse models suggest that these phenotypes can be productively modified in the postnatal period through manipulation of TGF $\beta$ activity, plausibly including the use of drugs that are already in development or in use for other indications (unpublished data). These treatments have the potential to not only slow or prevent progression of aortic root aneurysms, but also to attenuate the multisystem pathogenesis of disease.

\section{Conclusions}

Progress in the past century has led to an improved understanding of the cause, pathophysiology, and treatment of Marfan's syndrome. As our knowledge of the consequences of fibrillin-1 deficiency develops, we anticipate that treatment will continue to advance, allowing improved length and quality of life for patients with the disorder. Indeed, Marfan's syndrome represents a paradigm success that foreshadows future challenges and opportunities that will derive from the human genome project and increased sophistication in the elucidation of the genetic basis of disease. As we modify the natural history of disease, it will be important to observe and respond to the new reality of ageing with selected genetic disorders, including Marfan's syndrome, which shows an already apparent predisposition for accelerated joint disease and a predisposition for primary involvement of the descending aorta in older individuals.

\section{Acknowledgments}

We thank Bart Loeys for helpful comments regarding this manuscript. Both authors receive funding from the United States National Institutes of Health and the National Marfan Foundation. H C Dietz receives funding from the Howard Hughes Medical Institute and the William S Smilow Center for Marfan Syndrome Research. D P Judge receives 
funding from the Dana and Albert "Cubby" Broccoli Center for Aortic Diseases. No specific funding was received to write this Seminar.

\section{References}

1. Marfan AB. Un cas de deformation congenitale des quarte membres plus prononcee aux extremites caracterisee par l'allongement des os avec un certain degre d'amincissement. Bull Mem Soc Med Hop Paris 1986;13:220-26.

2. Gray JR, Bridges AB, Faed MJ, et al. Ascertainment and severity of Marfan syndrome in a Scottish population. J Med Genet 1994;31:51-54. [PubMed: 8151638]

3. Dietz HC, Cutting GR, Pyeritz RE, et al. Marfan syndrome caused by a recurrent de novo missense mutation in the fibrillin gene. Nature 1991;352:337-39. [PubMed: 1852208]

4. Loeys B, De Backer J, Van Acker P, et al. Comprehensive molecular screening of the FBN1 gene favors locus homogeneity of classical Marfan syndrome. Hum Mutat 2004;24:140-46. [PubMed: 15241795]

5. Kinoshita N, Mimura J, Obayashi C, Katsukawa F, Onishi S, Yamazaki H. Aortic root dilatation among young competitive athletes: echocardiographic screening of 1929 athletes between 15 and 34 years of age. Am Heart J 2000;139:723-28. [PubMed: 10740158]

6. Murdoch JL, Walker BA, Halpern BL, Kuzma JW, McKusick VA. Life expectancy and causes of death in the Marfan syndrome. N Engl J Med 1972;286:804-08. [PubMed: 5011789]

7. Silverman DI, Burton KJ, Gray J, et al. Life expectancy in the Marfan syndrome. Am J Cardiol 1995;75:157-60. [PubMed: 7810492]

8. Beighton P, de Paepe A, Danks D, et al. International Nosology of Heritable Disorders of Connective Tissue, Berlin, 1986. Am J Med Genet 1988;29:581-94. [PubMed: 3287925]

9. De Paepe A, Devereux RB, Dietz HC, Hennekam RC, Pyeritz RE. Revised diagnostic criteria for the Marfan syndrome. Am J Med Genet 1996;62:417-26. [PubMed: 8723076]

10. Joseph KN, Kane HA, Milner RS, Steg NL, Williamson MB Jr, Bowen JR. Orthopedic aspects of the Marfan phenotype. Clin Orthop Relat Res 1992;277:251-61. [PubMed: 1555349]

11. Maumenee IH. The eye in the Marfan syndrome. Trans Am Ophthalmol Soc 1981;79:684-733. [PubMed: 7043871]

12. McKusick VA. The cardiovascular aspects of Marfan's syndrome. Circulation 1955;11:321 [PubMed: 14352380]

13. Sisk HE, Zahka KG, Pyeritz RE. The Marfan syndrome in early childhood: analysis of 15 patients diagnosed at less than 4 years of age. Am J Cardiol 1983;52:353-58. [PubMed: 6869287]

14. Pyeritz RE, Wappel MA. Mitral valve dysfunction in the Marfan syndrome. Clinical and echocardiographic study of prevalence and natural history. Am J Med 1983;74:797-807. [PubMed: 6837604]

15. Roberts WC, Honig HS. The spectrum of cardiovascular disease in the Marfan syndrome: a clinicomorphologic study of 18 necropsy patients and comparison to 151 previously reported necropsy patients. Am Heart J 1982;104:115-35. [PubMed: 7046406]

16. Chen S, Fagan LF, Nouri S, Donahoe JL. Ventricular dysrhythmias in children with Marfan's syndrome. Am J Dis Child 1985;139:273-76. [PubMed: 3976608]

17. Savolainen A, Kupari M, Toivonen L, Kaitila I, Viitasalo M. Abnormal ambulatory electrocardiographic findings in patients with the Marfan syndrome. J Intern Med 1997;241:221-26. [PubMed: 9104435]

18. Meijboom LJ, Timmermans J, van Tintelen JP, et al. Evaluation of left ventricular dimensions and function in Marfan's syndrome without significant valvular regurgitation. Am J Cardiol 2005;95:795-97. [PubMed: 15757617]

19. Roman MJ, Devereux RB, Kramer-Fox R, O'Loughlin J. Two-dimensional echocardiographic aortic root dimensions in normal children and adults. Am J Cardiol 1989;64:507-12. [PubMed: 2773795]

20. Gott VL, Cameron DE, Alejo DE, et al. Aortic root replacement in 271 Marfan patients: a 24-year experience. Ann Thorac Surg 2002;73:438-43. [PubMed: 11845856]

21. Gott VL, Greene PS, Alejo DE, et al. Replacement of the aortic root in patients with Marfan's syndrome. N Engl J Med 1999;340:1307-13. [PubMed: 10219065] 
22. Spittell PC, Spittell JA Jr, Joyce JW, et al. Clinical features and differential diagnosis of aortic dissection: experience with 236 cases (1980 through 1990). Mayo Clin Proc 1993;68:642-51. [PubMed: 8350637]

23. Debakey ME, Henly WS, Cooley DA, Morris GC, Crawford ES, Beal AC. Surgical management of dissecting aneurysms of the aorta. J Thorac Cardiovasc Surg 1965;49:130-49. [PubMed: 14261867]

24. Streeten EA, Murphy EA, Pyeritz RE. Pulmonary function in the Marfan syndrome. Chest 1987;91:408-12. [PubMed: 3816319]

25. Wood JR, Bellamy D, Child AH, Citron KM. Pulmonary disease in patients with Marfan syndrome. Thorax 1984;39:780-84. [PubMed: 6495247]

26. Cohen PR, Schneiderman P. Clinical manifestations of the Marfan syndrome. Int J Dermatol 1989;28:291-99. [PubMed: 2666320]

27. Pyeritz RE, Fishman EK, Bernhardt BA, Siegelman SS. Dural ectasia is a common feature of the Marfan syndrome. Am J Hum Genet 1988;43:726-32. [PubMed: 3189335]

28. Villeirs GM, Van Tongerloo AJ, Verstraete KL, Kunnen MF, De Paepe AM. Widening of the spinal canal and dural ectasia in Marfan's syndrome: assessment by CT. Neuroradiology 1999;41:850-54. [PubMed: 10602862]

29. Fattori R, Nienaber CA, Descovich B, et al. Importance of dural ectasia in phenotypic assessment of Marfan's syndrome. Lancet 1999;354:910-13. [PubMed: 10489951]

30. Glesby MJ, Pyeritz RE. Association of mitral valve prolapse and systemic abnormalities of connective tissue. A phenotypic continuum. JAMA 1989;262:523-28. [PubMed: 2739055]

31. Montgomery RA, Geraghty MT, Bull E, et al. Multiple molecular mechanisms underlying subdiagnostic variants of Marfan syndrome. Am J Hum Genet 1998;63:1703-11. [PubMed: 9837823]

32. Tsipouras P, Del Mastro R, Sarfarazi M, et al. Genetic linkage of the Marfan syndrome, ectopia lentis, and congenital contractural arachnodactyly to the fibrillin genes on chromosomes 15 and 5 . The International Marfan Syndrome Collaborative Study. N Engl J Med 1992;326:905-09. [PubMed: 1542340]

33. Vaughan CJ, Casey M, He J, et al. Identification of a chromosome 11q23.2-q24 locus for familial aortic aneurysm disease, a genetically heterogeneous disorder. Circulation 2001;103:2469-75. [PubMed: 11369687]

34. Guo D, Hasham S, Kuang SQ, et al. Familial thoracic aortic aneurysms and dissections: genetic heterogeneity with a major locus mapping to 5q13-14. Circulation 2001;103:2461-68. [PubMed: 11369686]

35. Gale AN, McKusick VA, Hutchins GM, Gott VL. Familial congenital bicuspid aortic valve: secondary calcific aortic stenosis and aortic aneurysm. Chest 1977;72:668-70. [PubMed: 913155]

36. Loeys BL, Chen J, Neptune ER, et al. A syndrome of altered cardiovascular, craniofacial, neurocognitive, and skeletal development caused by mutations in TGFBR1 or TGFBR2. Nat Genet 2005;37:275-81. [PubMed: 15731757]

37. Shprintzen RJ, Goldberg RB. A recurrent pattern syndrome of craniosynostosis associated with arachnodactyly and abdominal hernias. J Craniofac Genet Dev Biol 1982;2:65-74. [PubMed: 6182156]

38. Greally MT, Carey JC, Milewicz DM, et al. Shprintzen-Goldberg syndrome: a clinical analysis. Am J Med Genet 1998;76:202-12. [PubMed: 9508238]

39. Furlong J, Kurczynski TW, Hennessy JR. New Marfanoid syndrome with craniosynostosis. Am J Med Genet 1987;26:599-604. [PubMed: 3565476]

40. Halme T, Savunen T, Aho H, Vihersaari T, Penttinen R. Elastin and collagen in the aortic wall: changes in the Marfan syndrome and annuloaortic ectasia. Exp Mol Pathol 1985;43:1-12. [PubMed: 4007138]

41. Tsuji T. Marfan syndrome: demonstration of abnormal elastic fibres in skin. J Cutan Pathol 1986;13:144-53. [PubMed: 3722521]

42. Takebayashi S, Kubota I, Takagi T. Ultrastructural and histochemical studies of vascular lesions in Marfan's syndrome, with report of 4 autopsy cases. Acta Pathol Jpn 1973;23:847-66. [PubMed: 4274046] 
43. Kainulainen K, Pulkkinen L, Savolainen A, Kaitila I, Peltonen L. Location on chromosome 15 of the gene defect causing Marfan syndrome. N Engl J Med 1990;323:935-39. [PubMed: 2402262]

44. Fazio MJ, Mattei MG, Passage E, et al. Human elastin gene: new evidence for localization to the long arm of chromosome 7. Am J Hum Genet 1991;48:696-703. [PubMed: 2014796]

45. Sakai LY, Keene DR, Engvall E. Fibrillin, a new 350-kD glycoprotein, is a component of extracellular microfibrils. J Cell Biol 1986;103:2499-509. [PubMed: 3536967]

46. Kainulainen K, Steinmann B, Collins F, et al. Marfan syndrome: no evidence for heterogeneity in different populations, and more precise mapping of the gene. Am J Hum Genet 1991;49:662-67. [PubMed: 1882844]

47. Corson GM, Chalberg SC, Dietz HC, Charbonneau NL, Sakai LY. Fibrillin binds calcium and is coded by cDNAs that reveal a multidomain structure and alternatively spliced exons at the $5 \beta$ end. Genomics 1993;17:476-84. [PubMed: 7691719]

48. Biery NJ, Eldadah ZA, Moore CS, Stetten G, Spencer F, Dietz HC. Revised genomic organization of FBN1 and significance for regulated gene expression. Genomics 1999;56:70-77. [PubMed: 10036187]

49. Reinhardt DP, Mechling DE, Boswell BA, Keene DR, Sakai LY, Bachinger HP. Calcium determines the shape of fibrillin. J Biol Chem 1997;272:7368-73. [PubMed: 9054436]

50. Reinhardt DP, Ono RN, Sakai LY. Calcium stabilizes fibrillin-1 against proteolytic degradation. J Biol Chem 1997;272:1231-36. [PubMed: 8995426]

51. Hollister DW, Godfrey M, Sakai LY, Pyeritz RE. Immunohistologic abnormalities of the microfibrillar-fiber system in the Marfan syndrome. N Engl J Med 1990;323:152-59. [PubMed: 2194127]

52. Nijbroek G, Sood S, McIntosh I, et al. Fifteen novel FBN1 mutations causing Marfan syndrome detected by heteroduplex analysis of genomic amplicons. Am J Hum Genet 1995;57:8-21. [PubMed: 7611299]

53. Dietz HC, McIntosh I, Sakai LY, et al. Four novel FBN1 mutations: significance for mutant transcript level and EGF-like domain calcium binding in the pathogenesis of Marfan syndrome. Genomics 1993;17:468-75. [PubMed: 8406497]

54. Halliday D, Hutchinson S, Kettle S, Firth H, Wordsworth P, Handford PA. Molecular analysis of eight mutations in FBN1. Hum Genet 1999;105:587-97. [PubMed: 10647894]

55. Judge DP, Biery NJ, Keene DR, et al. Evidence for a critical contribution of haploinsufficiency in the complex pathogenesis of Marfan syndrome. J Clin Invest 2004;114:172-81. [PubMed: 15254584]

56. Hutchinson S, Furger A, Halliday D, et al. Allelic variation in normal human FBN1 expression in a family with Marfan syndrome: a potential modifier of phenotype. Hum Mol Genet 2003;12:2269_ 76. [PubMed: 12915484]

57. Pereira L, Andrikopoulos K, Tian J, et al. Targetting of the gene encoding fibrillin-1 recapitulates the vascular aspect of Marfan syndrome. Nat Genet 1997;17:218-22. [PubMed: 9326947]

58. Pereira L, Lee SY, Gayraud B, et al. Pathogenetic sequence for aneurysm revealed in mice underexpressing fibrillin-1. Proc Natl Acad Sci USA 1999;96:3819-23. [PubMed: 10097121]

59. Bunton TE, Biery NJ, Myers L, Gayraud B, Ramirez F, Dietz HC. Phenotypic alteration of vascular smooth muscle cells precedes elastolysis in a mouse model of Marfan syndrome. Circ Res 2001;88:37-43. [PubMed: 11139471]

60. Ramirez F, Rifkin DB. Cell signaling events: a view from the matrix. Matrix Biol 2003;22:101-07. [PubMed: 12782137]

61. Pereira L, D'Alessio M, Ramirez F, et al. Genomic organization of the sequence coding for fibrillin, the defective gene product in Marfan syndrome. Hum Mol Genet 1993;2:1762. [PubMed: 8268958]

62. Saharinen J, Hyytiainen M, Taipale J, Keski-Oja J. Latent transforming growth factor-beta binding proteins (LTBPs) — structural extracellular matrix proteins for targeting TGF-beta action. Cytokine Growth Factor Rev 1999;10:99-117. [PubMed: 10743502]

63. Massague J. How cells read TGF-beta signals. Nat Rev Mol Cell Biol 2000;1:169-78. [PubMed: 11252892]

64. Neptune ER, Frischmeyer PA, Arking DE, et al. Dysregulation of TGF-beta activation contributes to pathogenesis in Marfan syndrome. Nat Genet 2003;33:407-11. [PubMed: 12598898] 
65. Ng CM, Cheng A, Myers LA, et al. TGF-beta-dependent pathogenesis of mitral valve prolapse in a mouse model of Marfan syndrome. J Clin Invest 2004;114:1586-92. [PubMed: 15546004]

66. Jones KB, Myers L, Judge DP, Kirby PA, Dietz HC, Sponseller PD. Toward an understanding of dural ectasia: a light microscopy study in a murine model of Marfan syndrome. Spine 2005;30:29193. [PubMed: 15682009]

67. Mizuguchi T, Collod-Beroud G, Akiyama T, et al. Heterozygous TGFBR2 mutations in Marfan syndrome. Nat Genet 2004;36:855-60. [PubMed: 15235604]

68. Collod-Beroud G, Beroud C, Ades L, et al. Marfan Database (third edition): new mutations and new routines for the software. Nucleic Acids Res 1998;26:229-33. [PubMed: 9399842]

69. Loeys B, Nuytinck L, Delvaux I, De Bie S, De Paepe A. Genotype and phenotype analysis of 171 patients referred for molecular study of the fibrillin-1 gene FBN1 because of suspected Marfan syndrome. Arch Intern Med 2001;161:2447-54. [PubMed: 11700157]

70. Pereira L, Levran O, Ramirez F, et al. A molecular approach to the stratification of cardiovascular risk in families with Marfan's syndrome. N Engl J Med 1994;331:148-53. [PubMed: 8008028]

71. Judge DP, Biery NJ, Dietz HC. Characterization of microsatellite markers flanking FBN1: utility in the diagnostic evaluation for Marfan syndrome. Am J Med Genet 2001;99:39-47. [PubMed: 11170092]

72. Lonnqvist L, Child A, Kainulainen K, Davidson R, Puhakka L, Peltonen L. A novel mutation of the fibrillin gene causing ectopia lentis. Genomics 1994;19:573-76. [PubMed: 8188302]

73. Faivre L, Gorlin RJ, Wirtz MK, et al. In frame fibrillin-1 gene deletion in autosomal dominant WeillMarchesani syndrome. J Med Genet 2003;40:34-36. [PubMed: 12525539]

74. Dagoneau N, Benoist-Lasselin C, Huber C, et al. ADAMTS10 mutations in autosomal recessive Weill-Marchesani syndrome. Am J Hum Genet 2004;75:801-06. [PubMed: 15368195]

75. Eldadah ZA, Grifo JA, Dietz HC. Marfan syndrome as a paradigm for transcript-targeted preimplantation diagnosis of heterozygous mutations. Nat Med 1995;1:798-803. [PubMed: 7585183]

76. Marr JE, Halliwell-Ewen J, Fisher B, Soler L, Ainsworth JR. Associations of high myopia in childhood. Eye 2001;15:70-74. [PubMed: 11318301]

77. Loewenstein A, Barequet IS, De Juan E Jr, Maumenee IH. Retinal detachment in Marfan syndrome. Retina 2000;20:358-63. [PubMed: 10950412]

78. Jones KB, Erkula G, Sponseller PD, Dormans JP. Spine deformity correction in Marfan syndrome. Spine 2002;27:2003-12. [PubMed: 12634560]

79. Arn PH, Scherer LR, Haller JA Jr, Pyeritz RE. Outcome of pectus excavatum in patients with Marfan syndrome and in the general population. J Pediatr 1989;115:954-58. [PubMed: 2585234]

80. Quigley PM, Haller JA Jr, Jelus KL, Loughlin GM, Marcus CL. Cardiorespiratory function before and after corrective surgery in pectus excavatum. J Pediatr 1996;128:638-43. [PubMed: 8627435]

81. Borowitz D, Cerny F, Zallen G, et al. Pulmonary function and exercise response in patients with pectus excavatum after Nuss repair. J Pediatr Surg 2003;38:544-47. [PubMed: 12677562]

82. Bawazir OA, Montgomery M, Harder J, Sigalet DL. Midterm evaluation of cardiopulmonary effects of closed repair for pectus excavatum. J Pediatr Surg 2005;40:863-67. [PubMed: 15937832]

83. Lawson ML, Mellins RB, Tabangin M, et al. Impact of pectus excavatum on pulmonary function before and after repair with the Nuss procedure. J Pediatr Surg 2005;40:174-80. [PubMed: 15868581] discussion 180

84. Nuss D, Kelly J, Robert E, Croitoru DP, Katz ME. A 10-year review of a minimally invasive technique for the correction of pectus excavatum. J Pediatr Surg 33:545-52. [PubMed: 9574749]

85. Haller J, Colombani PM, Humphries CT, Azizkhan RG, Loughlin GM. Chest wall constriction after too extensive and too early operations for pectus excavatum. Anns Thorac Surg 1996;61:1618-25.

86. Halpern BL, Char F, Murdoch JL, Horton WB, McKusick VA. A prospectus on the prevention of aortic rupture in the Marfan syndrome with data on survivorship without treatment. Johns Hopkins Med J 1971;129:123-29. [PubMed: 5113220]

87. Salim MA, Alpert BS, Ward JC, Pyeritz RE. Effect of beta-adrenergic blockade on aortic root rate of dilation in the Marfan syndrome. Am J Cardiol 1994;74:629-33. [PubMed: 7915491] 
88. Rossi-Foulkes R, Roman MJ, Rosen SE, et al. Phenotypic features and impact of beta blocker or calcium antagonist therapy on aortic lumen size in the Marfan syndrome. Am J Cardiol 1999;83:1364-68. [PubMed: 10235096]

89. Shores J, Berger KR, Murphy EA, Pyeritz RE. Progression of aortic dilatation and the benefit of longterm beta-adrenergic blockade in Marfan's syndrome. N Engl J Med 1994;330:1335-41. [PubMed: 8152445]

90. Henry WL, Gardin JM, Ware JH. Echocardiographic measurements in normal subjects from infancy to old age. Circulation 1980;62:1054-61. [PubMed: 7418156]

91. Yetman AT, Bornemeier RA, McCrindle BW. Usefulness of enalapril versus propranolol or atenolol for prevention of aortic dilation in patients with the marfan syndrome. Am J Cardiol 2005;95:112527. [PubMed: 15842990]

92. Davies RR, Goldstein LJ, Coady MA, et al. Yearly rupture or dissection rates for thoracic aortic aneurysms: simple prediction based on size. Ann Thorac Surg 2002;73:17-27. [PubMed: 11834007]

93. Bentall H, De Bono A. A technique for complete replacement of the ascending aorta. Thorax 1968;23:338-39. [PubMed: 5664694]

94. Bachet J, Termignon JL, Goudot B, et al. Aortic root replacement with a composite graft. Factors influencing immediate and long-term results. Eur J Cardiothorac Surg 1996;10:207-13. [PubMed: 8664022]

95. David TE, Feindel CM. An aortic valve-sparing operation for patients with aortic incompetence and aneurysm of the ascending aorta. J Thorac Cardiovasc Surg 1992;103:617-21. [PubMed: 1532219] discussion 622

96. Sarsam MA, Yacoub M. Remodeling of the aortic valve anulus. J Thorac Cardiovasc Surg 1993;105:435-38. [PubMed: 8445922]

97. de Oliveira NC, David TE, Ivanov J, et al. Results of surgery for aortic root aneurysm in patients with Marfan syndrome. J Thorac Cardiovasc Surg 2003;125:789-96. [PubMed: 12698141]

98. Birks EJ, Webb C, Child A, Radley-Smith R, Yacoub MH. Early and long-term results of a valvesparing operation for Marfan syndrome. Circulation 1999;100:1129-35.

99. Bethea BT, Fitton TP, Alejo DE, et al. Results of aortic valve-sparing operations: Experience with remodeling and reimplantation procedures in 65 patients. Ann Thorac Surg 2004;78:767-72. [PubMed: 15336989]

100. De Paulis R, De Matteis GM, Nardi P, et al. One-year appraisal of a new aortic root conduit with sinuses of Valsalva. J Thorac Cardiovasc Surg 2002;123:33-39. [PubMed: 11782753]

101. Braverman AC. Exercise and the Marfan syndrome. Med Sci Sports Exerc 1998;30:S387-95. [PubMed: 9789865]

102. Maron BJ, Chaitman BR, Ackerman MJ, et al. Recommendations for physical activity and recreational sports participation for young patients With genetic cardiovascular diseases. Circulation 2004;109:2807-16. [PubMed: 15184297]

103. Pyeritz RE. Maternal and fetal complications of pregnancy in the Marfan syndrome. Am J Med 1981;71:784-90. [PubMed: 7304650]

104. Rossiter JP, Repke JT, Morales AJ, Murphy EA, Pyeritz RE. A prospective longitudinal evaluation of pregnancy in the Marfan syndrome. Am J Obstet Gynecol 1995;173:1599-606. [PubMed: 7503207]

105. Meijboom LJ, Vos FE, Timmermans J, et al. Pregnancy and aortic root growth in the Marfan syndrome: a prospective study. Eur Heart J 2005;26:914-20. [PubMed: 15681576]

106. Vitale N, De Feo M, De Santo LS, Pollice A, Tedesco N, Cotrufo M. Dose-dependent fetal complications of warfarin in pregnant women with mechanical heart valves. J Am Coll Cardiol 1999;33:1637-41. [PubMed: 10334435]

107. Lev-Ran O, Kramer A, Gurevitch J, Shapira I, Mohr R. Low-molecular-weight heparin for prosthetic heart valves: treatment failure. Ann Thorac Surg 2000;69:264-65. [PubMed: 10654529]

108. Ageno W, Crotti S, Turpie AG. The safety of antithrombotic therapy during pregnancy. Expert Opin Drug Saf 2004;3:113-18. [PubMed: 15006717]

109. Roberts N, Ross D, Flint SK, Arya R, Blott M. Thromboembolism in pregnant women with mechanical prosthetic heart valves anticoagulated with low molecular weight heparin. Bjog 2001;108:327-29. [PubMed: 11281477] 


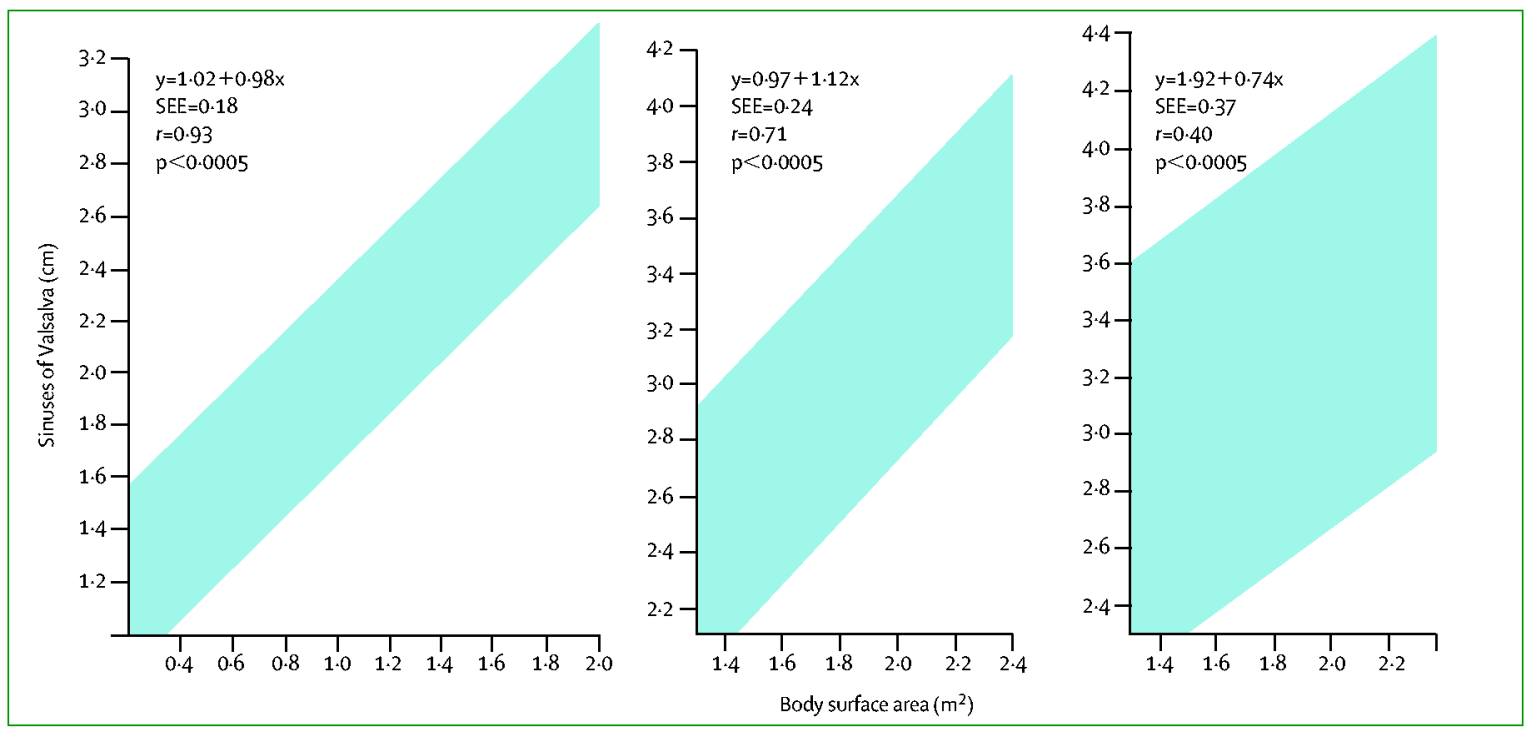

Figure:

Aortic root growth curves normalised to body size and age The left graph is for children and adolescents, the middle graph is for adults younger than 40 years, and the right graph is for adults older than 40 years. The shaded areas represent the range of values in which $95 \%$ of the population will fall. Modified from The American Journal of Cardiology with permission of Elsevier. 
Differential diagnosis of Marfan's syndrome

\begin{tabular}{|c|c|c|c|}
\hline & Cardiac involvement & Vascular involvement & Systemic features \\
\hline MASS (\#604308) & Mitral valve prolapse & $\begin{array}{l}\text { Borderline/non-progressive aortic } \\
\text { root enlargement }\end{array}$ & $\begin{array}{l}\text { Non-specific skin and skeletal } \\
\text { findings, myopia }\end{array}$ \\
\hline $\begin{array}{l}\text { Familial thoracic aortic aneurysm } \\
(\# 132900)\end{array}$ & None & Sinus of Valsalva aortic aneurysm & None \\
\hline BAV with AoA (\#109730) & Bicuspid aortic valve & $\begin{array}{l}\text { Sinus of Valsalva, ascending } \\
\text { aortic, and/or cerebral aneurysm }\end{array}$ & None \\
\hline Familial ectopia lentis (\#129600) & None & None & $\begin{array}{l}\text { Lens dislocation, mild non- } \\
\text { specific skeletal features }\end{array}$ \\
\hline $\begin{array}{l}\text { Ehlers-Danlos syndrome, type IV } \\
(\# 130050)\end{array}$ & Mitral valve prolapse & $\begin{array}{l}\text { Aneurysm and rupture of any } \\
\text { medium or large muscular artery }\end{array}$ & $\begin{array}{l}\text { Joint hypermobility, atrophic } \\
\text { scars, easy bruising, hernias, } \\
\text { rupture of hollow organs }\end{array}$ \\
\hline Homocystinuria (\#236200) & Mitral valve prolapse & Intravascular thrombosis & $\begin{array}{l}\text { Tall stature, ectopia lentis, long- } \\
\text { bone overgrowth, mental } \\
\text { retardation }\end{array}$ \\
\hline Loeys-Dietz syndrome (\#609192) ${ }^{*}$ & $\begin{array}{l}\text { Patent ductus } \\
\text { arteriosus; atrial septal } \\
\text { defect, bicuspid aortic } \\
\text { valve }\end{array}$ & $\begin{array}{l}\text { Sinus of Valsalva aneurysm, } \\
\text { arterial tortuosity, aneurysms in } \\
\text { other arteries }\end{array}$ & $\begin{array}{l}\text { Hypertelorism, cleft palate, } \\
\text { broad or bifid uvula, exotropia, } \\
\text { craniosynostosis, malar } \\
\text { hypoplasia, blue sclerae, } \\
\text { dolichostenomelia, } \\
\text { arachnodactyly, pectus } \\
\text { deformity, scoliosis, joint laxity, } \\
\text { rare developmental delay, }\end{array}$ \\
\hline $\begin{array}{l}\text { Sphrintzen- } \\
\text { Goldberg syndrome (\#182212) }\end{array}$ & None & Rare Sinus of Valsalva aneurysm & $\begin{array}{l}\text { Hypertelorism, } \\
\text { craniosynostosis, arched palate, } \\
\text { arachnodactyly, pectus } \\
\text { deformity,scoliosis, joint laxity, } \\
\text { developmental delay }\end{array}$ \\
\hline
\end{tabular}

MASS=mitral, aortic, skin, and skeletal manifestations. BAV=bicommissural aortic valve. AoA=ascending aortic aneurysm. Differential diagnoses are listed with their Online Mendelian Inheritance in Man (OMIM) numbers.

*

* These disorders may show substantial overlap with Marfan's syndrome in many organ systems. Thus, it is not only important to consider what findings are consistent with Marfan's syndrome in patients under assesment, but also findings that are not expected to be seen in Marfan's syndrome. 